\title{
Preterm birth among African American and white women: a multilevel analysis of socioeconomic characteristics and cigarette smoking
}

\author{
J Ahern, K E Pickett, S Selvin, B Abrams
}

See end of article for authors' affiliations

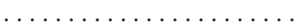

Correspondence to: Jennifer Ahern, Center for Urban Epidemiologic Studies, New York Academy of Medicine, 12165 th Avenue, Room 553, New York, NY 10029, USA jahern@nyam.org

Accepted for publication 27 November 2002

\begin{abstract}
Study objective: Research shows that neighbourhood socioeconomic factors are associated with preterm delivery. This study examined whether cigarette smoking and individual socioeconomic factors modify the effects of neighbourhood factors on preterm delivery.

Design: Case-control study.

Setting: Moffit Hospital in San Francisco, California.

Participants: 417 African American and 1244 white women, including all preterm and a random selection of term deliveries 1980-1990, excluding non-singleton pregnancies, congenital anomolies, induced deliveries, and women transported for special care. US census data from 1980 and 1990 were used to characterise the women's neighbourhoods, defined as census tracts.

Results: Cigarette smoking increased the risk of preterm delivery among both African American (OR=1.77, 95\% confidence intervals $(\mathrm{Cl})(1.12$ to 2.79$))$ and white women $(\mathrm{OR}=1.25,95 \% \mathrm{Cl}(1.01$ to 1.55)). However, cigarette smoking did not attenuate or modify the association of neighbourhood factors with preterm delivery. Among African American women, having public insurance modified the relation between neighbourhood unemployment and preterm delivery; among women without public insurance, the risk of preterm delivery was low in areas with low unemployment and high in areas with high unemployment, while among women with public insurance the risk of preterm delivery was highest at low levels of neighbourhood unemployment.

Conclusions: Cigarette smoking was associated with preterm delivery, especially among African Americans. Adverse neighbourhood conditions had an influence on preterm delivery beyond that of cigarette smoking. The effects of some neighbourhood characteristics were different depending on individual socioeconomic status. Examining socioeconomic and behavioural/biological risk factors together may increase understanding of the complex causes of preterm delivery.
\end{abstract}

$P$ reterm birth is a leading cause of perinatal mortality in the United States (US). ${ }^{12}$ Infants born before 37 completed weeks of gestation are also at higher risk of infections and neurodevelopmental problems. ${ }^{1}$ The rate of preterm delivery in the US in 1996 was substantial at 97.3/1000 liveborn infants. ${ }^{2}$ Of particular note, the risk of preterm delivery for African American mothers is about twice that for white mothers, ${ }^{34}$ and the established biological and behavioural risk factors for preterm delivery do not explain this disparity in risk. ${ }^{5}$

A small set of studies have examined the impact of ecological socioeconomic factors on birth outcomes, ${ }^{6-17}$ although, to our knowledge, only one included neighbourhood risk factors for preterm delivery. ${ }^{6}$ In that study, neighbourhood characteristics had a non-linear relation with preterm delivery and the significant characteristics were different for African American and white women. ${ }^{6}$ Almost all studies of neighbourhood socioeconomic factors and birth outcomes control for individual level socioeconomic characteristics, ${ }^{6-15}$ but few have examined the interrelations between individual and neighbourhood level characteristics. ${ }^{10}$ One study found interactions between individual and neighbourhood level factors in relation to low birth weight showing that the effects of neighbourhood conditions differ based on individual socioeconomic status. ${ }^{10}$

Smoking is one of the most important individual level risk behaviours that affect preterm delivery. ${ }^{18-29}$ Recent estimates suggest that $10 \%-20 \%$ of women smoke during pregnancy. ${ }^{30}{ }^{31}$ Cigarette smoking is of particular interest when considering the importance of neighbourhood socioeconomic factors because it is a risk behaviour that would plausibly be affected by neighbourhood factors (for example, by behavioural norms), ${ }^{32}$ and a risk behaviour that may have a greater impact on preterm delivery when combined with adverse neighbourhood conditions (for example, various stressors have been shown to activate neuroendocrine response mechanisms). . $^{33-37}$

We were therefore interested in the roles of neighbourhood social characteristics, cigarette smoking, and individual socioeconomic characteristics in preterm delivery. We integrated insights from work by $\mathrm{O}^{\prime} \mathrm{C} a m p o$ with approaches for studying preterm delivery in African American women suggested by Rowley and colleagues to create the following theoretical model of preterm delivery ${ }^{3}{ }^{10}$ : the social environment has a direct effect on preterm delivery by affecting susceptibility to disease, an indirect effect by shaping certain risk behaviours, and the effects of the social environment on preterm delivery may differ depending on individual characteristics and behaviours.

In line with this conceptual model we explored the complexities of the relation between neighbourhood characteristics and preterm delivery building on previous research on neighbourhood factors and preterm delivery. ${ }^{6}$ We examined whether some of the effect of the neighbourhood socioeconomic conditions on preterm delivery could be explained by different smoking behaviour within some neighbourhoods, and whether the effects of neighbourhood conditions were different depending on a mother's smoking. We also examined whether individual socioeconomic status modified the effects of neighbourhood characteristics on preterm delivery. 
Table 1 Census tract level neighbourhood variables from the 1980 and 1990 US census

Variables from 1990

Proportion of African American residents

Proportion of adults with less than a high school education

Proportion of unemployed adult men*

Proportion of people in poverty

Proportion of people in working class occupations $†$

Proportion of households in poverty

Median income
Variables from the Change between 1980-1990

Change in the proportion of African American residents

Change in the proportion of adults with less than a high school education

Change in the proportion of unemployed adult men *

Change in the proportion of people in poverty

Change in the proportion of people in working class occupations $\dagger$

*Adults defined as persons 18 years of age or older. WWorking class occupation defined as in Krieger $1991 .{ }^{8}$

\section{METHODS}

Data for this case-control study were drawn from a cohort of all live births at Moffit Hospital, University of California at San Francisco (UCSF) between 1980 and 1990 (17 146 deliveries). Human subjects approval was granted by the University of California at Berkeley and the USCF. We selected all African American and white singleton preterm deliveries as cases and two random selections of singleton term deliveries as controls, stratified into African American and white infants. We excluded two groups from the analysis: (1) women with nonsingleton pregnancies, infants with congenital anomalies, and induced deliveries as the aetiology of preterm deliveries in these situations differs substantially from spontaneous preterm singleton deliveries, ${ }^{4} 339$ and (2) women who were transported for special care from other hospitals or regions because they did not represent the population base for this study.

The eligible analytical cohort included 417 African American and 1244 white women. We used standard methods to abstract data from the medical records as previously described. ${ }^{6}$ Each woman's address was linked to census tract data from the 1980 and 1990 US census through geocoding techniques. Census tracts contain about 4000 people and were originally defined to encompass neighbourhood areas. ${ }^{40}$

We created 12 census tract level neighbourhood variables from the 1980 and 1990 US census data. These variables, detailed in table 1 , were selected to characterise the neighbourhood social environment by aggregating characteristics that have been used to examine individual level SES, as well as those that might reflect racial segregation. We examined the change in variables between 1980-1990 to identify neighbourhoods in flux and assess trends in neighbourhoods.

The outcome of interest in this study, preterm delivery, was defined as delivery before 37 completed weeks of gestation. ${ }^{41}$ The main individual level determinant of interest, cigarette smoking, was measured as cigarettes per day, self reported at the first prenatal care visit. Individual level covariates of the effect of cigarette smoking on preterm delivery considered in the analysis, included insurance coverage as Medi-Cal (California public insurance) compared with other (private insurance or payment by patient), maternal age at delivery in years, maternal height in centimetres, pre-pregnancy weight in kilograms, and parity.

All analyses were conducted separately for African American and white women. In the neighbourhood level analysis we used regression models with generalised estimating equations to generate parameter estimates accounting for both the individual and neighbourhood levels of the data. ${ }^{42}$ We modelled the risk of each neighbourhood variable alone on preterm delivery, controlling for Medi-Cal insurance coverage to adjust for individual level socioeconomic status. Neighbourhood variables were included with squared terms to accommodate the non-linear functional form of their relations with preterm delivery in both descriptive and multivariable analysis. The neighbourhood level variables with $95 \%$ confidence intervals on the combined main effect and squared terms that did not overlap the null were presented. The neighbourhood variables included in the initial models were included together in one model for African American women and one for white women.

We used logistic regression for the analysis of the effect of smoking on preterm delivery, including cigarette smoking and potential confounders. Cigarette smoking was modelled as cigarettes per day in all models.

After estimating the effect of neighbourhood and smoking independently on preterm delivery we added cigarettes per day to each of the neighbourhood models to determine whether this would change or remove the effect of the area level variables. We examined all potential cross level interactions of cigarettes per day and Medi-Cal insurance coverage with each neighbourhood variable in the final models for African American and white women. Plots of the odds ratios corresponding to values of the neighbourhood variables over the range of the data were constructed; these plots illustrate the relations between the neighbourhood variables and preterm delivery given the complexity of interpreting squared area level terms and interaction terms from parameter estimates alone.

\section{RESULTS}

The bivariate relations between demographic characteristics and preterm delivery for African American and white women are presented in table 2. Among African American and white women, the preterm cases had indicators of lower socioeconomic status and smoked more cigarettes per day, compared with controls. The African American women delivering preterm also had slightly lower non-pregnant weight, and slightly higher parity.

The first contextual model for the African American women contained three neighbourhood characteristics: median tract income in 1990, proportion of unemployed men in the tract in 1990, and the change in the proportion of African American residents between 1980 and 1990 (table 3). These neighbourhood characteristics had significant squared terms, indicating non-linear $\mathrm{U}$ shaped relations between the variables and preterm delivery. The first contextual model for white women had only one neighbourhood variable: the change in the proportion of unemployed men in the tract between 1980 and 1990 (table 3). This neighbourhood characteristic had a significant squared term, indicating a $U$ shaped relation between the change in unemployment and the risk of preterm delivery. These associations have been demonstrated in another publication by the authors. ${ }^{6}$

We examined the risk of preterm delivery attributable to smoking in the single level multivariable logistic regression analysis, controlling for Medi-Cal insurance, parity, maternal height, and non-pregnant weight. The model for African American women demonstrated that smoking is a risk factor for preterm delivery. The odds ratio for preterm delivery for every 10 cigarettes smoked per day was $1.77,95 \%$ CI ( 1.12 to 2.79) (table 4). Smoking also increased the risk of preterm 
Table 2 Demographic and medical characteristics for cases of preterm delivery and controls, UCSF cohort 1980-1990

\begin{tabular}{|c|c|c|c|c|c|c|c|c|}
\hline \multirow{3}{*}{$\begin{array}{l}\text { Characteristic } \\
\text { Maternal age: mean (SE) }\end{array}$} & \multicolumn{4}{|c|}{ African American women } & \multicolumn{4}{|c|}{ White women } \\
\hline & \multicolumn{2}{|c|}{ Case $n=116^{*}$} & \multicolumn{2}{|c|}{ Control $n=301^{*}$} & \multicolumn{2}{|c|}{ Case $n=242^{*}$} & \multicolumn{2}{|c|}{ Control $n=1002^{*}$} \\
\hline & 25.0 & 0.50 & 25.3 & 0.30 & 28.9 & 0.36 & 28.7 & 0.17 \\
\hline Parity: mean (SE) & 1.2 & 0.12 & 1.0 & 0.07 & 0.75 & 0.07 & 0.74 & 0.03 \\
\hline Maternal height $(\mathrm{cm})$ : mean (SE) & 163.5 & 0.63 & 164.4 & 0.39 & 163.8 & 0.40 & 164.5 & 0.22 \\
\hline Non-pregnant weight $(\mathrm{kg})$ : mean (SE) & 61.2 & 1.28 & 65.3 & 0.95 & 59.4 & 0.76 & 61.1 & 0.40 \\
\hline Smoking (cigarettes/day): mean (SE) & 4.01 & 0.67 & 1.98 & 0.29 & 3.02 & 0.34 & 2.20 & 0.19 \\
\hline \multicolumn{9}{|l|}{ Insurance status: $n(\%)$} \\
\hline Medi-Cal & 70 & 64.2 & 158 & 53.2 & 53 & 23.6 & 171 & 17.4 \\
\hline Private or self pay & 39 & 35.8 & 139 & 46.8 & 172 & 76.4 & 814 & 82.6 \\
\hline \multicolumn{9}{|l|}{ Marital status: $\mathrm{n}(\%)$} \\
\hline Married & 28 & 24.6 & 99 & 33.0 & 171 & 72.5 & 742 & 74.7 \\
\hline Single/divorced/widowed & 86 & 75.4 & 201 & 67.0 & 65 & 27.5 & 251 & 25.3 \\
\hline \multicolumn{9}{|l|}{ Maternal education: $\mathrm{n}(\%)$} \\
\hline Less than high school & 19 & 21.6 & 27 & 10.5 & 15 & 6.8 & 47 & 5.1 \\
\hline High school graduate or greater & 69 & 78.4 & 231 & 89.5 & 205 & 93.2 & 873 & 94.9 \\
\hline \multicolumn{9}{|l|}{ Family occupation: $\mathrm{n}(\%)$} \\
\hline Working class & 84 & 72.4 & 196 & 66.9 & 86 & 35.7 & 293 & 29.4 \\
\hline Non-working class & 32 & 27.6 & 97 & 33.1 & 155 & 64.3 & 703 & 70.6 \\
\hline
\end{tabular}

delivery among white women. The odds ratio for preterm delivery for every 10 cigarettes smoked per day was $1.25,95 \%$ CI ( 1.01 to 1.55 ) (table 4$)$.

Examining the combined effect of neighbourhood and smoking among African American women, adding cigarettes per day to the neighbourhood model only slightly changed the parameter estimates for median income, proportion unemployed, and change in the proportion of African American residents (table 3). There was no evidence of interactions between cigarette smoking and these neighbourhood variables. However, there was significant interaction between Medi-Cal insurance and proportion of unemployed male residents in 1990. Among white women, the association between change in unemploy- ment and preterm delivery remained significant when adjusting for cigarette smoking. The parameter estimates for change in unemployment were slightly greater in this model (table 3). There was no evidence of cross level interaction between cigarette smoking or Medi-Cal status and change in unemployment for white women. Odds ratios corresponding to values of each neighbourhood variable for selected percentiles are presented in graphs, along with 95\% confidence intervals (fig lA-E). The risk of preterm delivery for African American women was increased in neighbourhoods with low median income (fig 1A). Among African American women who were not covered by Medi-Cal, the risk of preterm delivery was low in neighbourhoods with low unemployment and high in

Table 3 Multilevel logistic models of tract level socioeconomic variables and individual level Medi-Cal: examining the impact of cigarettes smoked per day, UCSF Cohort 1980-1990

\begin{tabular}{|c|c|c|c|c|c|c|}
\hline \multirow[b]{2}{*}{ Variable* } & \multicolumn{2}{|c|}{$\begin{array}{l}\text { Model without smoking or } \\
\text { interactions }\end{array}$} & \multicolumn{2}{|c|}{ Model with interactions } & \multicolumn{2}{|c|}{$\begin{array}{l}\text { Model with smoking and } \\
\text { interactions }\end{array}$} \\
\hline & $\begin{array}{l}\text { Parameter } \\
\text { estimate }\end{array}$ & $\mathrm{p}$ Value & $\begin{array}{l}\text { Parameter } \\
\text { estimate } \neq\end{array}$ & p Value & $\begin{array}{l}\text { Parameter } \\
\text { estimate }\end{array}$ & $\mathrm{p}$ Value \\
\hline \multicolumn{7}{|l|}{ African American women, $n=354$} \\
\hline Cigarettes per day & - & - & - & - & 0.0577 & 0.0012 \\
\hline Medi-Cal insurance & 0.4904 & 0.0726 & 2.9432 & 0.0006 & 2.8204 & 0.0011 \\
\hline Median income & -0.0177 & 0.1727 & -0.0233 & 0.0713 & -0.0171 & 0.2243 \\
\hline Median income ${ }^{2}$ & 0.0020 & 0.0012 & 0.0023 & 0.0002 & 0.0020 & 0.0014 \\
\hline Proportion unemployed & 18.7145 & 0.0002 & 44.3926 & 0.0001 & 43.1257 & 0.0001 \\
\hline Proportion unemployed ${ }^{2}$ & -69.9021 & $<0.00005$ & -138.6252 & 0.0002 & -129.4735 & 0.0003 \\
\hline Change in African American & 8.1161 & 0.0020 & 8.2689 & 0.0039 & 8.7025 & 0.0035 \\
\hline Change in African American ${ }^{2}$ & 34.8994 & 0.0011 & 31.9562 & 0.0063 & 32.3387 & 0.0093 \\
\hline Medi-Cal $\times p$ unemployed & - & - & -39.9200 & 0.0049 & -38.4063 & 0.0070 \\
\hline \multirow[t]{2}{*}{ Medi-Cal $\times p$ unemployed ${ }^{2}$} & - & - & 105.7676 & 0.0197 & 97.4579 & 0.0286 \\
\hline & \multicolumn{2}{|c|}{$\begin{array}{l}\text { Model without cigarette } \\
\text { smoking }\end{array}$} & \multicolumn{4}{|c|}{ Model with cigarette smoking } \\
\hline Variable† & $\begin{array}{l}\text { Parameter } \\
\text { estimate } \ddagger\end{array}$ & $\mathrm{p}$ Value & $\begin{array}{l}\text { Parameter } \\
\text { estimatef }\end{array}$ & $\mathrm{p}$ Value & & \\
\hline \multicolumn{7}{|l|}{ White women, $n=1142$} \\
\hline Cigarettes per day & - & - & 0.0169 & 0.1525 & & \\
\hline Medi-Cal insurance & 0.3833 & 0.0368 & 0.3368 & 0.0638 & & \\
\hline Change in unemployed & -3.3248 & 0.1212 & -3.5530 & 0.0917 & & \\
\hline Change in unemployed ${ }^{2}$ & 76.9932 & $<0.00005$ & 78.2600 & $<0.00005$ & & \\
\hline \multicolumn{7}{|c|}{$\begin{array}{l}\text { * Median income, median income in the census tract in } 1990 \text {, centred and divided by } 1000 \text {. Proportion unemployed, proportion of unemployed men }>18 \\
\text { years old in the census tract in } 1990 \text {. Change in African American, change in the proportion of African American residents in the census tract between } \\
1980-1990 \text {. Medi-Cal } \times p \text { unemployed, interaction term between the proportion of unemployed men in } 1990 \text { and Medi-Cal insurance coverage. } \\
\text { †Change in unemployed, change in the proportion of unemployed men }>18 \text { years old in the census tract in between } 1980-1990 \text {. } \ddagger \text { Parameter estimates } \\
\text { are interpreted as in a logistic model with squared term, for example, } O R=e^{\wedge}\left(-3.5530 \times \text { change in unemployed }+78.2600 \times \text { change in unemployed }^{2}\right) \text { for } \\
\text { the change in proportion of unemployed men among white women. }\end{array}$} \\
\hline
\end{tabular}


Table 4 Logistic models of the effect of cigarette smoking on preterm delivery for African American and white women

\begin{tabular}{|c|c|c|c|}
\hline Variable & Parameter estimate* & SE & $\mathrm{p}$ Value \\
\hline \multicolumn{4}{|c|}{ African American women, $n=346$} \\
\hline Intercept & 1.67 & 3.23 & 0.61 \\
\hline Cigarettes per day & 0.057 & 0.023 & 0.015 \\
\hline Medi-Cal insurance & 0.20 & 0.26 & 0.45 \\
\hline Parity & 0.073 & 0.10 & 0.49 \\
\hline Maternal height $(\mathrm{cm})$ & -0.013 & 0.020 & 0.53 \\
\hline Non-pregnant weight $(\mathrm{kg})$ & -0.017 & 0.010 & 0.097 \\
\hline \multicolumn{4}{|l|}{ White women, $n=1153$} \\
\hline Intercept & 1.14 & 1.86 & 0.54 \\
\hline Cigarettes per day & 0.022 & 0.011 & 0.046 \\
\hline Medi-Cal insurance & 0.34 & 0.19 & 0.072 \\
\hline Parity & -0.0065 & 0.076 & 0.93 \\
\hline Maternal height $(\mathrm{cm})$ & -0.013 & 0.012 & 0.26 \\
\hline Non-pregnant weight $(\mathrm{kg})$ & -0.0098 & 0.0072 & 0.17 \\
\hline
\end{tabular}

neighbourhoods with greater proportions of unemployment (fig 1B). However, African American women who were covered by Medi-Cal were at high risk of preterm delivery at low levels of unemployment, with some reduction in risk at higher levels of unemployment (fig $1 \mathrm{C}$ ). In neighbourhoods with increasing proportions of African American residents, African American women were at increased risk of preterm delivery, and the relation was reversed in neighbourhoods with decreasing proportions of African American residents (fig lD). White women were at increased risk of preterm delivery in neighbourhoods with both increasing and decreasing levels of unemployment (fig lE).

\section{DISCUSSION}

Our analyses suggest that neighbourhood socioeconomic characteristics may have an impact on preterm delivery for African American and white women that is largely independent of cigarette smoking and may be modified by individual socioeconomic characteristics. Smoking was a risk factor for preterm delivery in adjusted models and had a stronger impact on the likelihood of preterm delivery in African American women than in white women. Neighbourhood socioeconomic factors did not interact with cigarette smoking. Among African American women, the effect of neighbourhood level unemployment was different depending on
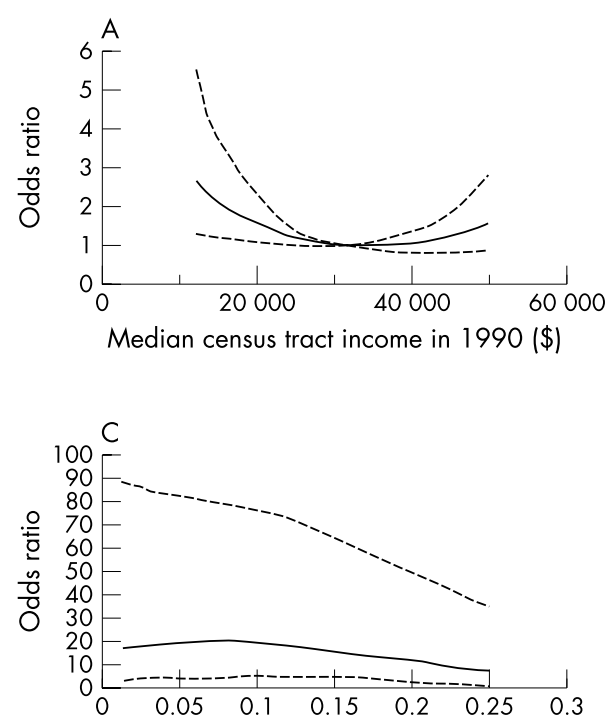

Proportion of unemployed men in the census tract in 1990

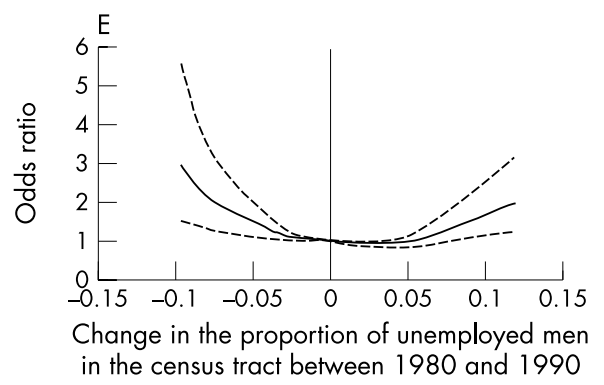

Figure 1 Odds ratios and 95\% confidence intervals for preterm delivery by census tract characteristics among African American and white women, UCSF cohort 1980-1990. (A) African American women: ORs for preterm delivery by median tract income. (B) African American women without Medi-Cal insurance: ORs for preterm delivery by proportion of unemployed men. (C) African American women with Medi-Cal insurance: ORs for preterm delivery by proportion of unemployed men. (D) African American women: ORs for preterm delivery by change in the proportion of African American residents. (E) White women: ORs for preterm delivery by change in the proportion of unemployed men. 
whether the women had Medi-Cal insurance coverage or not; women with Medi-Cal coverage had a high risk of preterm delivery with some reduction in risk at higher levels of unemployment, while women without Medi-Cal coverage had an increasing likelihood of preterm delivery at higher levels of neighbourhood unemployment.

In our analysis of cigarette smoking as an individual level risk factor, smoking was associated with preterm delivery among both African American and white women. The association between smoking and preterm delivery was stronger among African American women than it was among white women, which is consistent with previous studies. ${ }^{425}{ }^{43}$

Recent research indicates that smoking may interact biologically in women with recurring bacterial vaginosis (BV), increasing the likelihood of an episode of BV, which is a risk factor for preterm delivery. ${ }^{44-50}$ Recurring $\mathrm{BV}$ is also far more common among African Americans. ${ }^{45}{ }^{49-51}$ Although the reasons for more prevalent BV among African Americans are unknown, it may explain part of the differential impact of smoking on preterm delivery in this racial/ethnic group. This finding merits further exploration with data on smoking, BV and preterm delivery.

Smoking could have explained some of the association between neighbourhood factors and preterm delivery as maternal smoking may be influenced by normative behaviours and stresses in neighbourhoods. ${ }^{32}$ Research on the effects of stress and smoking on pregnant women offers a biological explanation for the increased risk of preterm delivery among women who both smoke and live in poor neighbourhoods (possibly through the synergistic effects of smoking and stress on raising catecholamine levels) ${ }^{33-37}$ However, our results suggest that the effects of neighbourhood characteristics were not affected by cigarette smoking.

Individual level Medi-Cal insurance coverage modified the impact of neighbourhood unemployment on preterm delivery. For African American women who were not covered by MediCal insurance and had more economic resources the risk of preterm delivery was low when neighbourhood unemployment was low and increased when unemployment was higher. This is plausible because women who may not have experienced major individual level socioeconomic hardship may still have experienced a negative impact on their birth outcomes if the neighbourhood was in poor economic condition. ${ }^{17}$ However, the relation was quite different for women who were covered by Medi-Cal insurance and had fewer economic resources. These women were already at high risk of preterm delivery with low unemployment in the neighbourhood. The risk of preterm delivery among women with Medi-Cal insurance was somewhat lower in neighbourhoods with higher unemployment. These women may have experienced the highest risk in areas with the lowest unemployment because they were impoverished in relation to the others in that neighbourhood. ${ }^{14}$ This finding is consistent with O'Campo's study of low birth weight, which found that the increased risk of low birth weight for women on Medicaid was decreased in neighbourhoods with low per capita income compared with neighbourhoods with high per capita income. $^{10}$

There are several limitations to this study. The findings of a hospital based study are not easily generalised to broader populations. If white women from more prosperous areas who thought they were at high risk of preterm delivery chose Moffit Hospital because of its tertiary care capacity, the increased risk of preterm delivery in neighbourhoods with decreasing unemployment (a potential indicator of improving social conditions) could be an artefact. Census data are only available for the beginning of each decade, so it is difficult to know how well this information represents the conditions of the tracts throughout the decade. In addition, census data do not capture all aspects of neighbourhoods that may affect health, ${ }^{52}$ and do not include information about the other com- munities (for example, workplace, school) to which these women may belong. Neighbourhood factors have not been studied sufficiently to determine which factors best characterise social conditions; thus, the neighbourhood characteristics examined in this study are necessarily exploratory. Our measure of smoking, self reported cigarettes per day at the first prenatal care visit, is limited because some women may not accurately report smoking. It is most probable that some smokers are misclassified as non-smokers and not vice versa creating a conservative estimate of the effect of smoking on preterm delivery. Smoking at the beginning of pregnancy may not represent smoking throughout pregnancy, particularly in the third trimester when smoking has the greatest impact on preterm delivery. ${ }^{263}$ Additionally, the small sample size of the African American subgroup and the modelling of interaction led to imprecise estimates of the effect of neighbourhood unemployment.

Notwithstanding these limitations, we demonstrated associations between neighbourhood socioeconomic characteristics and preterm delivery for both African American and white women that are independent of cigarette smoking and modified by individual socioeconomic characteristics. In addition, we found that cigarette smoking increases the risk of preterm delivery particularly among African American women. A better understanding of the differential influence of factors such as cigarette smoking on African American women may additionally help elucidate racial disparities in preterm delivery. Examining neighbourhood and individual socioeconomic factors in combination with behavioural and biological characteristics may lead to a better understanding of the complex causes of preterm delivery.

\section{ACKNOWLEDGEMENTS}

This study was supported by a grant from the California Wellness Foundation. We thank Katherine Hoggatt, Mi-Suk Kang, and Leann Prebil (Unversity of California at Berkeley School of Public Health) for analysis suggestions and discussions, and appreciate the helpful comments of Dr Sandro Galea (Center for Urban Epidemiologic Studies, New York Academy of Medicine).

\section{Authors' affiliations}

J Ahern, Center for Urban Epidemiologic Studies, New York Academy of Medicine, USA

K E Pickett, Departments of Health Studies and Obstetrics and Gynecology, University of Chicago, USA

S Selvin, Department of Biostatistics, University of California at Berkeley School of Public Health, USA

B Abrams, Department of Epidemiology, University of California at Berkeley School of Public Health

\section{REFERENCES}

1 Berkowitz GS, Papiernik E. Epidemiology of preterm birth. Epidemiol Rev 1993;15:414-43.

2 Centers for Disease Control and Prevention. Preterm singleton births-United States, 1989-1996. Morb Mortal Wkly Rep 1999:48: 185-9.

3 Rowley DL, Hogue CJR, Blackmore CA, et al. Preterm delivery among African-American women: a research strategy. Am J Prev Med 1993;9:1-6

4 Rolett A, Kiely JL. Maternal sociodemographic characteristics as risk factors for preterm birth in twins versus singletons. Paediatr Perinat Epidemiol 2000;14:211-18.

5 Kreiger N, Rowley D, Herman AA, et al. Racism, sexism and social class: implications for studies of health, disease and well-being. Am J Prev Med 1993;9:82-122.

6 Pickett KE, Ahern J, Selvin S, et al. Neighborhood socioeconomic status, maternal race and preterm delivery: a case-control study. Ann Epidemiol 2002; 12:410-18

7 Jarvelin MR, Elliott $P$, Kleinschmidt I, et al. Ecological and individual predictors of birthweight in a northern Finland birth cohort 1986. Paediatr Perinat Epidemiol 1997;11:298-312.

8 Krieger N. Women and social class: a methodological study comparing individual, household, and census measures as predictors of black/white differences in reproductive history. J Epidemiol Community Health $1991 ; 45: 35-42$

9 Matteson DW, Burr JA, Marshall JR. A multi-level analysis of individual and community risk factors. Soc Sci Med 1998;47:1841-54. 
10 O'Campo P, Xue X, Wang MC, et al. Neighborhood risk factors for low birthweight in Baltimore: a multilevel analysis. Am J Public Health 1997;87: $1113-18$

11 Morgan M, Chinn S. ACORN group, social class, and child health. J Epidemiol Community Health 1983;37:196-203.

12 Roberts EM. Neighborhood social environments and the distribution of low birthweight in Chicago. Am J Public Health 1997;87:187-204.

13 Slogett A, Joshi $H$. Deprivation indicators as predictors of life events 1981-1992 based on the UK ONS Longitudinal Study. J Epidemiol Community Health 1998;52:228-33.

14 Collins JW, Herman AA, David RJ. Very-low-birthweight infants and income incongruity among African American and white parents in Chicago. Am J Public Health 1997;87:414-17.

15 Fang J, Madhavan S, Alderman MH. Low birth weight: race and maternal nativity-impact of community income. Pediatrics 1999;103: 1-6.

16 Pearl M, Braveman P, Abrams B. The relationship of neighborhood socioeconomic characteristics to birthweight among 5 ethnic groups in California. Am J Public Health 2001:91:1808-14.

17 Catalano R, Hansen HT, Hartig T. The ecological effect of unemployment on the incidence of very low birthweight in Norway and Sweden. J Health Soc Behav 1999;40:422-8

18 Horta BL, Victora CG, Menezes AM, et al. Low birthweight, preterm births and intrauterine growth retardation in relation to maternal smoking. Paediatr Perinat Epidemiol 1997:11:140-51.

19 Kyrklund-Blomberg NB, Cnattingius S. Preterm birth and maternal smoking: risks related to gestational age and onset of delivery. Am J Obst Gynecol 1998;179:1051-5.

20 Meis PJ, Michielutte R, Peters TJ, et al. Factors associated with preterm birth in cardiff, wales. I. Univariable and multivariable analysis. Am J Obstet Gynecol 1995;173:590-6.

21 Meis PJ, Michielutte R, Peters TJ, et al. Factors associated with preterm birth in Cardiff, Wales. II. Indicated and spontaneous preterm birth. Am J Obstet Gynecol 1995;173:597-602.

22 Olsen $\mathbf{P}$, Laara E, Rantakallio $\mathrm{P}$, et al. Epidemiology of preterm delivery in two birth cohorts with an interval of 10 years. Am J Epidemiol 1995; 142: 1184-93

23 Peacock JL, Bland JM, Anderson HR. Preterm delivery: effects of socioeconomic factors, psychological stress, smoking, alcohol, and caffeine. BMU 1995:311:531-6.

24 Perkins SL, Belcher JM, Livesey JF. A Canadian tertiary care centre study of maternal and umbilical cord cotinine levels as markers of smoking during pregnancy: relationship to neonatal effects. Can J Public Health 1997:88:232-7.

25 Shah NR, Bracken MB. A Systematic review and meta-analysis of prospective studies on the association between maternal cigarette smoking and preterm delivery. Am J Obstet Gynecol 2000;1 182:465-72.

26 Wang X, Tager IB, Vunakis HV, et al. Maternal smoking during pregnancy, urine cotinine concentrations, and birth outcomes. A prospective cohort study. Int J Epidemiol 1997;26:978-8.

27 Wisborg K, Henriksen TB, Hedegaard M, et al. Smoking during pregnancy and preterm birth. Br J Obstet Gynaecol 1996;103:800-5.

28 Wu T, Buck G, Mendola P. Can regular multivitamin/mineral supplementation modify the relation between maternal smoking and select adverse birth outcomes. Ann Epidemiol 1998:8:175-83.

29 Zhang H, Bracken MB. Tree-based risk factor analysis of preterm delivery and small-for-gestational age birth. Am J Epidemiol 1995; 141:70-8

30 Andres RL, Day MC. Perinatal complications associated with maternal tobacco use. Semin Neonatol 2000;5:231-41.

31 Mathews TJ. Smoking during pregnancy in the 1990s. Natl Vital Stat Rep $2001 ; 49: 1-14$.
32 Pickett KE, Wakschlag LS, Leventhal BL, et al. The working-class context of smoking during pregnancy. Health Place 2002;8:167-75.

33 Istvan J. Stress, anxiety, and birth outcomes: a critical review of the evidence. Psychol Bull 1986;100:331-48.

34 Katz VL, Jenkins T, Haley L, et al. Catecholamine levels in pregnant physicians and nurses: a pilot study of stress and pregnancy. Obstet Gynecol 1991;77:338-42.

35 Quigley M, Sheehan K, Wilkes M, et al. Effects of maternal smoking on circulating catecholamine levels and fetal heart rates. Am J Obstet Gynecol 1979;133:685-90.

36 Katz VL, Miller NH, Bowes WA. Pregnancy complications of physicians. West J Med 1988;149:704-7.

37 Zuspan F, Cibils L, Pose S. Mytometrial and cardiovascular responses to alterations in plasma epinephrine and norepinephrine. Am J Obstet Gynecol 1962;84:841-51.

38 Wasserman CR, Shaw GM, Selvin S, et al. Socioeconomic status, neighborhood social conditions, and neural tube defects. Am J Public Health 1988;88:1674-80.

39 Pickett KE, Abrams B, Selvin S. Defining preterm delivery-the epidemiology of clinical presentation. Paediatr Perinat Epidemiol 2000; 14:305-8.

40 Census of Population and Housing. Summary tape file 3 on CD-ROM technical cocumentation. Washington, DC: Bureau of the Census, 1992.

41 Abrams B, Carmichael S, Selvin S. Factors associated with the pattern of maternal weight gain during pregnancy. Obstet Gynecol 1995;86:170-6.

42 Zeger SL, Liang K-Y. Longitudinal Data analysis for discrete and continuous outcomes. Biometrics 1986;42:121-30.

43 Ekwo EE, Moawad A. Maternal age and preterm births in a black population. Paediatr Perinat Epidemiol 2000;14:145-51.

44 Riduan J, Hillier S, Utomo B, et al. Bacterial vaginosis and prematurity in Indonesia: association in early and late pregnancy. Am J Obstet Gynecol $1993 ; 169: 175-8$

45 Hillier S, Nugent R, Eschenbach D, et al. Association between bacterial vaginosis and preterm delivery of a low-birth-weight infant. The Vaginal Infections and Prematurity Study Group. N Engl J Med 1995;333:1737-42.

46 Cu-Uvin S, Hogan J, Warren D, et al. Prevalence of lower denital tract infections among human immunodeficiency virus (hiv)-seropositive and high-risk hiv-seronegative women. HIV Epidemiology Research Study Group. Clin Infect Dis 1999;29:1 145-50.

47 Pastore L, Royce R, Jackson T, et al. Association between bacterial vaginosis and fetal fibronectin at 24-29 weeks gestation. Obstet Gynecol 1999;93:117-23.

48 Tchoudomirova K, Stanilova M, Garov V. Clinical Manifestations and diagnosis of vacterial vaginosis in a clinic of sexually transmitted diseases. Folia Med 1998;40:34-40.

49 Llahi-Camp J, Rai R, Ison C, et al. Association of bacterial vaginosis with a history of second trimester miscarriage. Hum Reprod 1996;11:1575-78.

50 Blackwell AL. Vaginal bacterial phaginosis? Sex Transm Infect 1999;75:352-3.

51 Goldenberg R, Klebanoff $M$, Nugent R, et al. Bacterial colonization of the vagina during pregnancy in four ethinc groups. Vaginal Infections and Prematurity Study Group. Am J Obstet Gynecol 1996;174:1618-

52 Pickett KE, Pearl M. Multilevel analyses of neighbourhood socioeconomic context and health outcomes: a critical review. J Epidemiol Community Health 2001;55:1 11-22.

53 Pickett KE, Wakschlag LS, Dai L, et al. Fluctuations of maternal smoking during pregnancy. Obstet Gynecol 2003;101:140-7. 